\title{
Design Analysis and Development of a Quad- Band Complementary Antenna Array for Wireless Application
}

\author{
Juin Acharjee ${ }^{1}$, Mrinmoy Chakraborty ${ }^{2}$ (Member IEEE) \\ Assistant Professor, ECE, NSHM Knowledge Campus, Durgapur, West Bengal, India ${ }^{1}$ \\ Assistant Professor, ECE, Dr. B.C. ROY Engineering College, Durgapur, West Bengal, India ${ }^{2}$
}

\begin{abstract}
In this paper a new complementary quad band omnidirectional planar microstrip antenna array has been proposed. This antenna consists of cascaded connection of three rectangular shaped patches on the upper side, two rectangular shaped patches on the ground side and one "I" shaped resonator at the ground to produce the effective structure of antenna array which can radiate omnidirectionally with high efficiency, moderate gain, low reflection and useful radiation pattern. This cascaded quad band antenna array operates at Bluetooth $(2.35-2.53) \mathrm{GHz}$, WIMAX (3.253.50) $\mathrm{GHz}$, HIPERLAN (4.06-4.30) GHz and WLAN (5.37-5.86) $\mathrm{GHz}$ with $\mathrm{S}_{11}<-10 \mathrm{~dB}$ and stable radiation pattern having gain $2.8 \mathrm{dBi}, 3.32 \mathrm{dBi}, 3.49 \mathrm{dbi}$,and $6.4 \mathrm{dBi}$ respectively. The bandwidth of these bands for proposed antenna becomes $180 \mathrm{MHz}, 250 \mathrm{MHz}, 240 \mathrm{MHz}$ and $490 \mathrm{MHz}$ respectively.
\end{abstract}

Keywords: Antenna array, BLUETOOTH, WIMAX, HIPERLAN, WLAN

\section{INTRODUCTION}

Microstrip antenna has become very popular in recent years due to its smaller size, comfortable to non-planar structure, low weight [1]. But microstrip antennas have a major disadvantage which is its low gain. Modern wireless communication system requires high gain omnidirectional antenna which can radiate omnidirectionally in azimuthal direction[2,3]. Due to low gain in conventional antenna it is not possible to cover the required region for wireless applications. For conventional application the vertical dipole antenna with half wavelength is the most popular choice. But it is not sufficient for wireless application. Moreover on the long wire antenna standing wave current distribution produces side lobes for each half section of the wavelength $[4,5]$.To overcome this problem a collinear array is the well known candidate. This novel idea of Collinear array (COA) was first given by Franklin [6]. He first designed COA from a long wire that had narrow Ushaped section to provide in phase feeding of the straight half wavelength parts of the longitudinal radiating wire antenna. Depending on this Franklin concept, Wheeler designed a COCO (Collinear Coaxial) antenna [7]. But the cost of the COCO antenna is very high because of its conformal cylindrical structure. To reduce the cost of this $\mathrm{COCO}$ antenna Bancroft and Brennan presented microstrip $\mathrm{COCO}$ antenna. This modified COCO antenna can be easily integrated with planar circuit and can also be fabricated very easily.

Various authors presented different types of planar microstrip omnidirectional antenna but most of these antennas had large size and low gain. In this work we basically proposed a compact quad band planar microstrip omnidirectional antenna. This antenna operates at BLUETOOTH (2.35-2.53) GHz, WIMAX(3.25-3.50) GHz, HIPERLAN (4.06-4.30) GHz and WLAN (5.37-5.86) GHz.
II ANTENNA STRUCTURE

The antenna has been simulated with HFSS software. The dimension of the proposed antenna is $(15 \times 79.08 \times 1.6)$ $\mathrm{mm}^{3}$. FR4 EPOXY substrate having dielectric constant 4.4 and loss tangent 0.02 has been used in this design. The complementary structure has been formed with keeping the three increasing order rectangular shaped patches on top of the dielectric substrate and the two rectangular shaped patches at the bottom of the dielectric substrate. The dimension of the upper patches are $(9 \times 16.1)$ $\mathrm{mm}^{2},(11.34 \times 17.2) \mathrm{mm}^{2}$ and $(12.53 \times 20.81) \mathrm{mm}^{2}$ respectively and the dimension for the lower patches are $(11.13 \times 17.05) \mathrm{mm}^{2}$ and $(12.69 \times 19.14) \mathrm{mm}^{2} . \quad A$ microstrip feed line having width $3 \mathrm{~mm}$ and length $7 \mathrm{~mm}$ have been used to feed the upper patches. A conical via is used for connecting the upper patches with the lower patches.

One I shaped SIR (Step Index Resonator) has been used for achieving HIPERLAN and WLAN bands properly. The length of the "I" shaped resonator is $18.3 \mathrm{~mm}$. This I shaped resonator plays an important role for getting two new bands and that are HIPERLAN and WLAN. Actually this resonator changes the current flowing path in the proposed antenna and due to the new current flowing path new frequencies are exited. Now the front view and back view of the single band antenna array are shown in figure 1 and 2 .

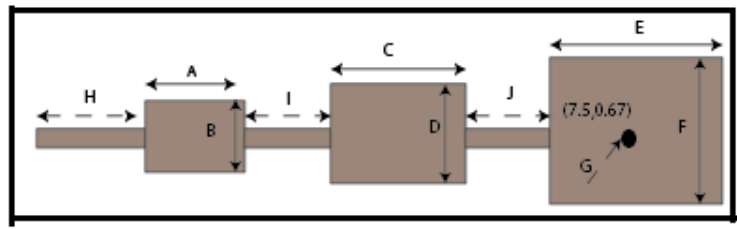

Figure 1: Front view of proposed Quadrature band Antenna 


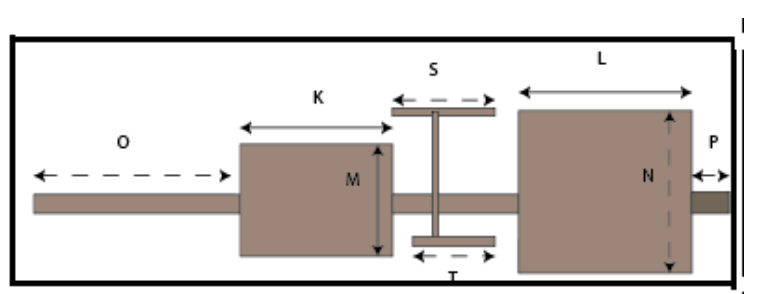

Figure 2 Back view of Proposed Quadrature band Antenna

Table 1: Dimension of different parameters of proposed Antenna

\begin{tabular}{|c|c|}
\hline Parameters & Values (in mm) \\
\hline A & 16.1 \\
\hline B & 9 \\
\hline C & 17.2 \\
\hline E & 11.3 \\
\hline F & 20.8 \\
\hline G & 3 \\
\hline H & $(7.5,0.67)$ \\
\hline I & 7 \\
\hline J & 14 \\
\hline K & 10.7 \\
\hline L & 17 \\
\hline M & 19.1 \\
\hline N & 11.1 \\
\hline O & 12.7 \\
\hline P & 19.8 \\
\hline S & 4.8 \\
\hline T & 5.8 \\
\hline
\end{tabular}

III PARAMETRIC STUDY

Three patches on the upper side, two patches on the lower side and one resonator in the lower side in combination helps to form a quad band antenna array. Now the effect of various patches on various positions on the dielectric changes the band in various sides. Some effects of these variations are discussed below-

The first patch which is close to the microstrip feed line is shifted to the left side from its current position then the bandwidth of the Bluetooth band is increased, the WIMAX band and HIPERLAN band is shifted to the left side and the bandwidth of the WLAN band is decreased. Similarly when that patch is shifted to the right side by 0.4 $\mathrm{mm}$ from its current position the bandwidth of the BLUETOOTH band, WIMAX band and HIPERLAN band is increased but the WLAN remains unchanged. Similar shifting in the right side by $0.8 \mathrm{~mm}$ increases the bandwidth of the BLUETOOTH band, WIMAX band and WLAN band but for this shifting the HIPERLAN band remains unchanged.

Now the next patch also changes the position of bands for the movement of this patch in the left side and right side. The bandwidth of the BULETOOTH band increases when this patch shifts to the left side by $0.4 \mathrm{~mm}$ but band shifts to the left side when that patch shifts in the left side by $0.6 \mathrm{~mm}$ and $0.8 \mathrm{~mm}$. The WIMAX band remains unchanged for $0.4 \mathrm{~mm}$ and $0.6 \mathrm{~mm}$ left movement of patch but bandwidth of the WIMAX band increases when the patch shifts in the left side by $0.6 \mathrm{~mm}$. The bandwidth of the HIPERLAN band decreases when patch shifts to the left side by $0.6 \mathrm{~mm}$ and $0.8 \mathrm{~mm}$ but band shifts to the left side when movement of patch is done by $0.4 \mathrm{~mm}$. Lastly for the WLAN band, bandwidth increases when the patch shifts to the left side by $0.6 \mathrm{~mm}$ and $0.8 \mathrm{~mm}$ but for $0.4 \mathrm{~mm}$ shifting the band only shifts to the left side. After that when the patch shifts to the right side by $0.4 \mathrm{~mm}, 0.6 \mathrm{~mm}$ and $0.8 \mathrm{~mm}$ simultaneously the bandwidth of the BLUETOOTH band increases for three cases, the WIMAX band remains unchanged for the first movement, shifts to the right side for the second movement and bandwidth increase for the third movement, the bandwidth of HIPERLAN band and WLAN band decreases for first case whereas for all other cases this HIPERLAN band remains unchanged but the WLAN band shifts to the right side for second case and remains unchanged for $0.8 \mathrm{~mm}$ movement.

Now the remaining patch on the dielectric in which shorting pin is paced changes the band in the right side and left side and many time it also increases the bandwidth of these bands. The bandwidth of the BLUETOOTH band increases when the patch shifts to the left side by $0.4 \mathrm{~mm}$ and right side by $0.6 \mathrm{~mm}$ and $0.8 \mathrm{~mm}$. The WIMAX band shifts to the right side when the patch shifts to the left side and $0.4 \mathrm{~mm}$ to the right side but that band remains unchanged when the patch shifts to the right side by $0.6 \mathrm{~mm}$ and $0.8 \mathrm{~mm}$. The HIPERLAN band shifts to the right side when the third patch shifts to the left side by $0.4 \mathrm{~mm}$ and $0.8 \mathrm{~mm}$ and right side by $0.4 \mathrm{~mm}$ and $0.6 \mathrm{~mm}$ whereas the bandwidth of this band decreases when patch shifts to the right side by $0.8 \mathrm{~mm}$. Lastly the WLAN band shifts to the left side when patch shifts to the left side by $0.4 \mathrm{~mm}, 0.6 \mathrm{~mm}$ and $0.8 \mathrm{~mm}$ and right side by $0.4 \mathrm{~mm}$ but for $0.6 \mathrm{~mm}$ shifts in the right side the band remains unchanged.

Now the patches which are placed on the ground plane also changes the position, increases the bandwidth of the BLUETOOTH band and WIMAX band, as this patch shifts to the left side whereas the bandwidth of the WLAN band decreases for $0.4 \mathrm{~mm}$ and $0.8 \mathrm{~mm}$ left shifting of patch. If the patch shifts to the right side by $0.4 \mathrm{~mm}$, $0.6 \mathrm{~mm}, 0.8 \mathrm{~mm}$ simultaneously the BLUETOOTH band shifts to the left side for three cases, bandwidth of the WIMAX band decreases for first two shifting but shifts to the right side for third case, bandwidth of the HIPERLAN band decreases for first shifting, increases for second shifting and shifts to the right side for third case and lastly the bandwidth of the WLAN band increases for second and third case whereas the band shifts to the left side for first case. The absence of the resonator which is placed at the reverse side of the proposed antenna eliminates the HIPERLAN band and WLAN bands completely. So after so many variations in the position of every patches of the proposed antenna changes the desired operating bands of the proposed antenna. Due to this optimized values of position and length of every patches has been taken for getting desired operating bands and that different parameters optimized values of proposed antenna is shown in Table 1. 
International Journal of Advanced Research in Computer and Communication Engineering Vol. 4, Issue 3, March 2015

\section{RESULT AND DISCUSSION}

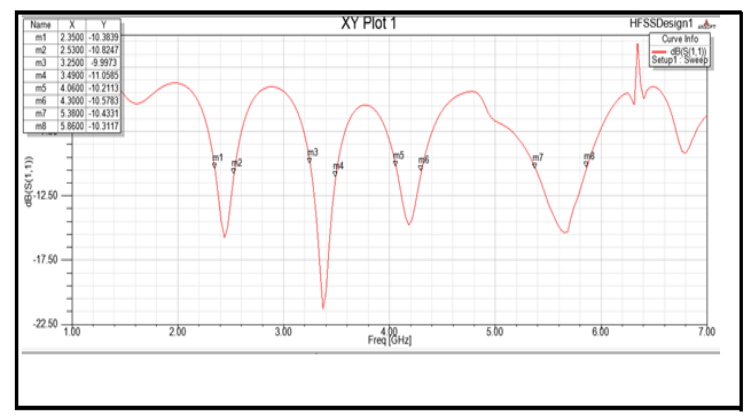

Figure 3: Simulated S-Parameter Display of Proposed Antenna

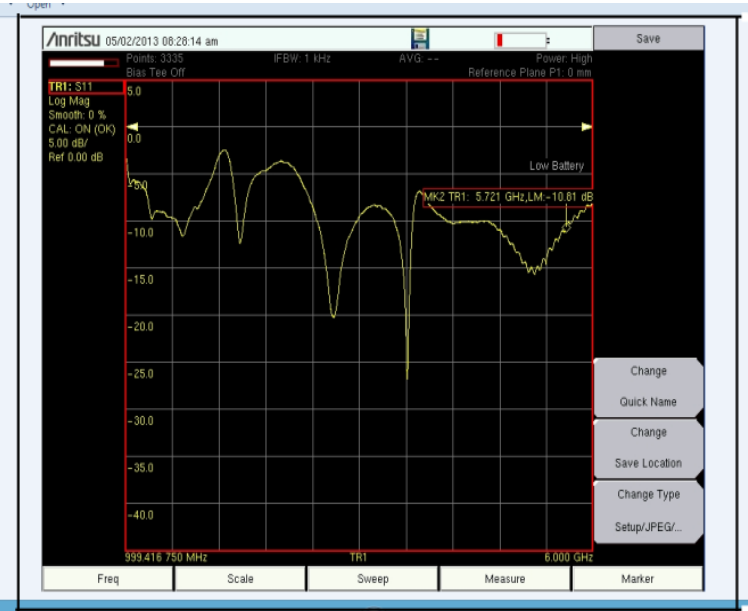

Figure 4: Measured S-parameter display of the proposed Quadrature Band Antenna

This antenna resonates at BLUETOOTH, WIMAX, HIPER LAN and WLAN band. The simulated and measured return loss curve of the proposed antenna is shown in Fig. $3 \& 4$. From the Fig 3, it is seen that it resonates at four different frequencies and that are 2.44 $\mathrm{GHz}, 3.37 \mathrm{GHz}, 4.18 \mathrm{GHz}$ and $5.65 \mathrm{GHz}$. At $2.44 \mathrm{GHz}$, $3.37 \mathrm{GHz}, 4.18 \mathrm{GHz}$ and $5.65 \mathrm{GHz}$ its return loss are -16 $\mathrm{dB},-22 \mathrm{~dB},-15 \mathrm{~dB}$ and $-16 \mathrm{~dB}$ respectively.

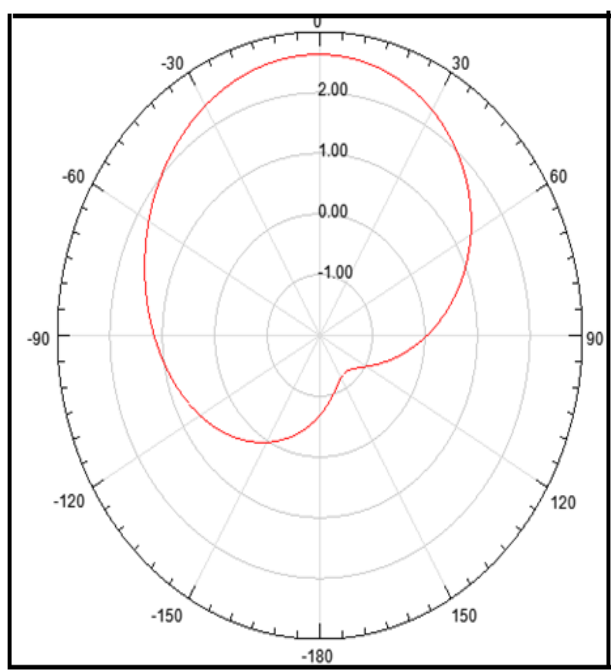

(a)

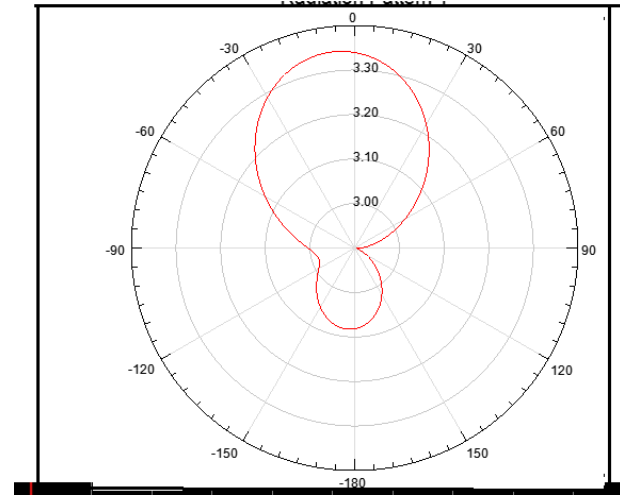

(b)

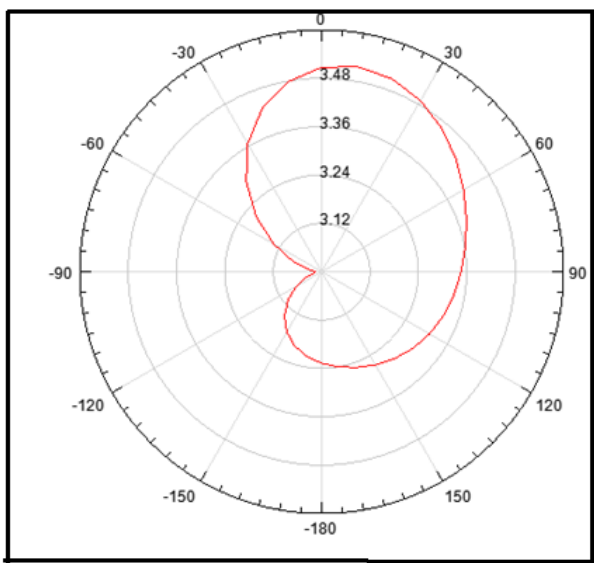

(c)

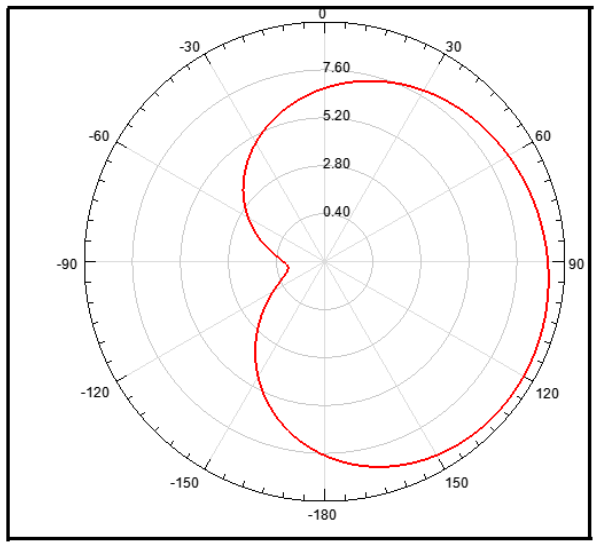

(d)

Fig 5: Radiation pattern of proposed antenna at (a) 2.44 $\mathrm{GHz}$ (c) $3.37 \mathrm{GHz}$ (b) $4.15 \mathrm{GHz}$ (d) $5.65 \mathrm{GHz}$

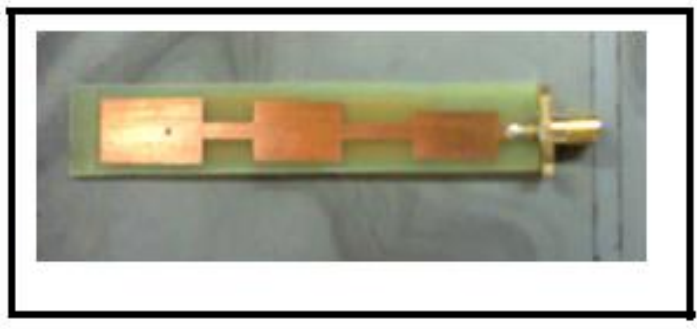

(a) Front View 


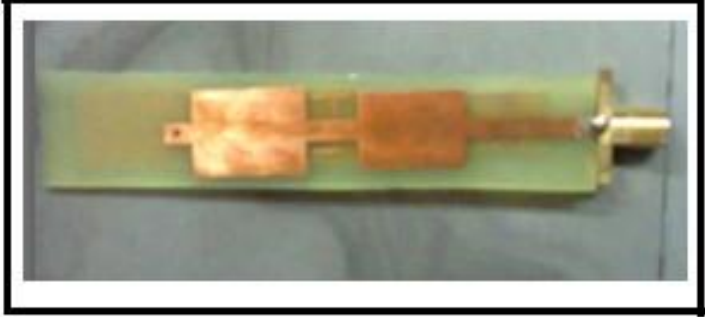

(b) Back View

Figure 8: Prototype of the Proposed Antenna

\section{CONCLUSION}

In this work we proposed a novel compact quad band microstrip omnidirectional antenna. This proposed antenna operates at four different frequencies and that are BLUETOOTH band, WIMAX band, HIPERLAN band and WLAN band having gain $2.8 \mathrm{dbi}, 3.32 \mathrm{dbi}, 3.49 \mathrm{dbi}$ and $6.4 \mathrm{dbi}$ respectively. There is good agreement between the simulated and measured result. This compact quad omnidirectional antenna can be effectively used at the specified wireless bands.

\section{REFERENCES}

[1]. Constantine A. Balanis, “Antenna Theory analysis And Design”,433-494.

[2]. Li, J. Y. J. L. Guo, Y. B. Gan, and Q. Z. Liu, "The tribandperformance of sleeve dipole antenna," Journal of ElectromagneticWaves and Applications, Vol. 19, No. 15, 2081-2092, 2005.

[3]. Khaleghi, A., "Diversity techniques with parallel dipole antennasnas: Radiation pattern analysis," Progress In ElectromagneticsResearch, Vol. 64, 23-42, 2006.

[4]. Franklin, C. S., "Improvements in wireless telegraph andtelephone aerials," British Patent, No. 242, 342, 1924.

[5]. Ghosh, S., A. Chakraborty, and S. Sanyal, "Loaded wire antennaas EMI sensor," Progress In Electromagnetics Research, Vol. 54, 19-36, 2005.

[6]. Solbach, K., "Microstrip-franklin antenna," IEEE Trans. Anten-nas Propagat., Vol. 30, No. 4, 773-775, 1982.

[7]. Judasz, T. J. and B. B. Balsley, "Improved theoretical andexperimental models for the coaxial colinear antenna," IEEETrans. Antennas Propagat., Vol. 37, 289-296, 1989.

[8]. K. P. Wei, Z. J. Zhang, and Z. H. Feng, "Design Of a dualband omnidirectional Planar microstrip antenna array" Progress In Electromagnetics Research, Vol. 126, 2012 pp. 101-120. 